\title{
SOBRE ALGUNOS TEXTOS DE MANUEL ROMERO DE TERREROS
}

Por Clementina Diaz y de Ovando

Conoci a Manuel Romero de Terreros, marqués de San Francisco, y de esto hace ya muchos años, en 1944, cuando el Instituto de Investigaciones Estéticas estaba en el tercer piso del anexo de la Escuela de Leyes, en la calle de San Ildefonso, frente a la Escuela Nacional Preparatoria. El edificio de la Escuela de Leyes con el cambio de esta escuela a la Ciudad Universitaria ha sufrido tantos cambios que el anexo desapareció.

Para llegar al Instituto se entraba por la Escuela de Leyes en medio de la algarabia estudiantil, unos días más entusiasta que otros, aquellos en que habia motivo de inquietud; ya fuera por el deseo de un cambio de autoridades universitarias, por alguna inconformidad o por el simple adelanto de las vacaciones. Después de subir esforzadamente por "una horrible escalera" en palabras de Francisco de la Maza, se entraba al Instituto. Su casa un enorme salón, con una mesa al centro, y a los lados los escritorios de los investigadores y de las secretarias.

El único y sobrio adorno eran unos viejos anaqueles de madera que guardaban valiosos libros, al cuidado de una seudobibliotecaria - tal atribución tenia-. La terrible custodia era de opinión que los libros no se debían consultar. El sitio de los volúmenes era el anaquel, no el escritorio de los investigadores.

A partir del traslado del Instituto a la Ciudad Universitaria, cuánto hemos mejorado. Nuestra especializada y valiosísima biblioteca está ahora al cuidado de un bibliotecario de carrera, y al servicio de la cultura mexicana, a ella acuden los estudiosos, principalmente jóvenes alumnos de diversas facultades, no sólo a consultar los libros, sino también, a pedir consejo a los investigadores en sus distintas especializaciones.

En aquel salón de San Ildefonso, entró el primero de octubre de 1946, a ocupar su puesto de investigador Manuel Romero de Terreros, destacado crítico de arte colonial. Hasta pocos días antes de su muerte fue todas las mañanas y a temprana hora al Instituto.

Alto, magro de carnes, de innata distinción, Romero de Terreros vestía con sencilla elegancia, casi siempre de gris oxford, sombrero, bastón, polainas en invierno a diferencia de su primo, el historiador Pablo 
Martínez del Río, que se distinguió por usar polainas en invierno o verano, en todas las estaciones, para sorpresa de muchos no acostumbrados ya a esta moda.

De trato afable, cordial, Romero de Terreros era a la vez un gentleman y un caballero que rezumaba cortesía mexicana.

Mi exaltado liberalismo, mi admiración por la Reforma, por los escritores liberales del siglo $\mathrm{xIx}$, a veces lo ponian en guardia, pues chocaban con su tradicional manera de pensar. Sin embargo, la discusión, si la hubo, nunca agria sino todo lo contrario franca y amable.

Habia muchos liberales que no se podian mencionar a Romero de Terreros. Pero entre los que sí se le podían, y más aún, le agradaba referirse a ellos estaban Mariano Riva Palacio y su hijo Vicente Riva Palacio. Muchas veces mostró su reconocimiento a la patriótica labor de Mariano Riva Palacio, amigo de uno de sus ascendientes. Es muy posible que Mariano Riva Palacio fuera amigo de aquel noble mexicano don Manuel de la Pedreguera y Romero de Terreros, quien protestó contra la Intervención francesa y el Imperio de Maximiliano cerrando su casa y marchándose a Europa antes que inclinarse al extranjero. A este don Manuel de la Pedreguera y Romero de Terreros ya sin darle ninguno de sus títulos, $E l$ Siglo $X I X$ de 18 de octubre de 1867, en su sección "Noticias nacionales", le dedica este encomiástico párrafo:

El C. Manuel Romero de Terreros. Pronto llegará a México esta persona que ha residido en el extranjero. Amante decidido de su patria, siempre contrario a la intervención y al imperio. Como a sus hermanos vio siem. pre a los hijos expatriados de México, a quienes prestó servicios de un extraordinario valor. Sea, pues bienvenido el Sr. Terreros.

Contaba Manuel Romero de Terreros que su familia sostuvo correspondencia con Mariano Riva Palacio y que en su poder quedaban algunas cartas. Reconocia y respetaba al escritor y general Vicente Riva Palacio, hijo de don Mariano y de Dolores Guerrero y, por tanto, nieto del prócer Vicente Guerrero.

Romero de Terreros que bien conocía la historia de la literatura mexicana, apreciaba el que Vicente Riva Palacio hubiera sido uno de los primeros en revalorar el pasado colonial, en reintegrar ese pasado a la historia de México, como lo demostró en el tomo segundo Historia de la dominación española en México desde 1521 a 1808, que forma parte de la obra monumental que dirigió: México a través de los siglos (1884-1889). 
También en lo literario Riva Palacio había sido pionero al ocuparse del pasado colonial. Algunos de sus famosos Cuentos del general (1896), se basan en episodios históricos que tomó de su propia Historia de la dominación española, como el cuento "Ciento por Uno" que debe haberlo escrito al tiempo de estar redactando la Historia, pues encuentro que apareció publicado en La Epaca Ilustrada el 26 de enero de 1885, con el título de "Tradiciones mexicanas históricas", 1 y dos años antes de 1887 en que lo publica otra vez en $E l$ siglo $X I X$, el 15 de septiembre de ese año. Cuentos de asunto colonial que resumió en Cuentos del general (1896). ${ }^{2}$

Riva Palacio hizo populares varios aspectos de la vida colonial mexicana y desde 1882 se ocupó en versificar la historia de las calles de México. El periódico La República, dirigido por el novelista Pedro Castera publicó una serie de leyendas en verso: "Tradiciones de México" en la que figuran leyendas como "La calle de Olmedo" (20 de febrero), "La calle de la Quemada" (27 de febrero), "El puente del clérigo" (6 de marzo), "La calle de la Joya" (19 de marzo). "La calle del Puente - Salto de Alvarado" (20 de marzo), "La mujer herrada", "Leyenda de la calle de la puerta falsa de Santo Domingo" (27 de marzo).

Estas leyendas están firmadas con el seudónimo Cero. Seudónimo que encubria a dos autores Vicente Riva Palacio y Juan de Dios Peza que a la limón escribieron las "Tradiciones de México", publicadas por La República.

Más tarde, una vez más, a la limón, Riva Palacio y Peza añadieron a las leyendas aparecidas en La Repriblica, otras sobre las calles de la ciudad de México, en donde contaban el porqué de los nombres de esas calles y otros sucesos de la Colonia. El volumen fue anunciado en los periódicos en 1887 como una edición de lujo, editado por J. Ballescá y Cía., y firmado por Vicente Riva Palacio y Peza.

Las Tradiciones y leyendas mexicanas de Riva Palacio y Peza, fueron muy apreciadas por Romero de Terreros. Junto con el profesor S. L. Millard Rosenberg, de la Universidad de California, preparó una edición de Tradiciones y leyendas como texto para los estudiantes de lengua

1. La Epaca Ilustrada, tomo n, núm. 13.

2 Existe nueva edición: Vicente Riva Palacio. Cuentos del general. Prólogo de Clementina Dlaz y de Ovando, México, Editorial Porrua, S.A., 1968, Col. "Sepan Cuantos...", núm. 101. 
española - hoy muy diff́cil de conseguir - y que adethás no figura en las bibliografias preparadas por Danilo Ongay y José Miguel Quintana. "

Tradiciones y leyendas mexicanas por Vicente Riva Palacio y Juan de Dios Peza, edited with introduction notes y vocabulary by Romero de Terreros (marqués de San Francisco) correspondiente de las Reales Academias Española y de la Historia de Madrid. Comendador de la Real Orden de Isabel la Católica, Caballero de Malta. And S. L. Millard Rosenberg, Ph. D. Associate professor of Spanish in the University of California at Los Angeles; corresponding Member of the Hispanic Society of America. Thomas Nelson and Sons. New York. 1927.

Romero de Terreres y S. L. Millard Rosenberg explican en el prólogo el porqué escogieron como libro de texto Tradiciones y leyendas.

Un creciente interés en la literatura mexicana ha conducido para la selección de Tradiciones y leyendas mexicanas por Riva Palacio y Peza, como un texto apropiado para estudios avanzados en español, en vista del atractivo y encanto del folklore mexicano -y especialmente del seductor ambiente de estos dos autores- y también porque los estudiantes encuentran en estas pintorescas leyendas una visión bastante objetiva de la "Nueva España", del México de antaño.

La primera edición de Tradiciones y leyendas contiene dieciocho leyendas. La de Romero de Terreros y Millard Rosenberg es una selección de estas leyendas: "El visitador Muñoz", "La mulata de Córdoba", "La llorona", "Don Juan Manuel", "La mujer herrada" y "La leyenda de la calle de Olmedo". Al hacer la selección tuvimos -dicen Romero de Terreros y Millard Rosenberg- estos motivos:

No todas las producciones realizadas en conjunto por Riva Palacio y Peza están incluidas en el presente texto. No todas las leyendas tienen igual excelencia, y ha sido nuestro propósito incluir aqul solamente aquellas que reúnen un mérito en general e interés histórico con la pureza de dicción. Aquí y alla se ha creído conveniente suprimir unas pocas de las lineas no del todo felices que disminuian la corriente ritmica de los poemas y distratan un tanto de su belleza.

- Bibliografias de los investigadores. Suplemento núm. 2 de los Anales del Instituto de Investigaciones Estéticas. México, 1961.

\$ Manuel Romero de Terreros. Bibliohemerografía. Sobretiro de la Secretarla de Hacienda Credito Publico, núm. 380, $1^{\text {t }}$ de noviembre de 1965.

- Agradezco a la sefota Róneto de Terreros que haya tenido la bondad de prestarme el raro ejemplar. 


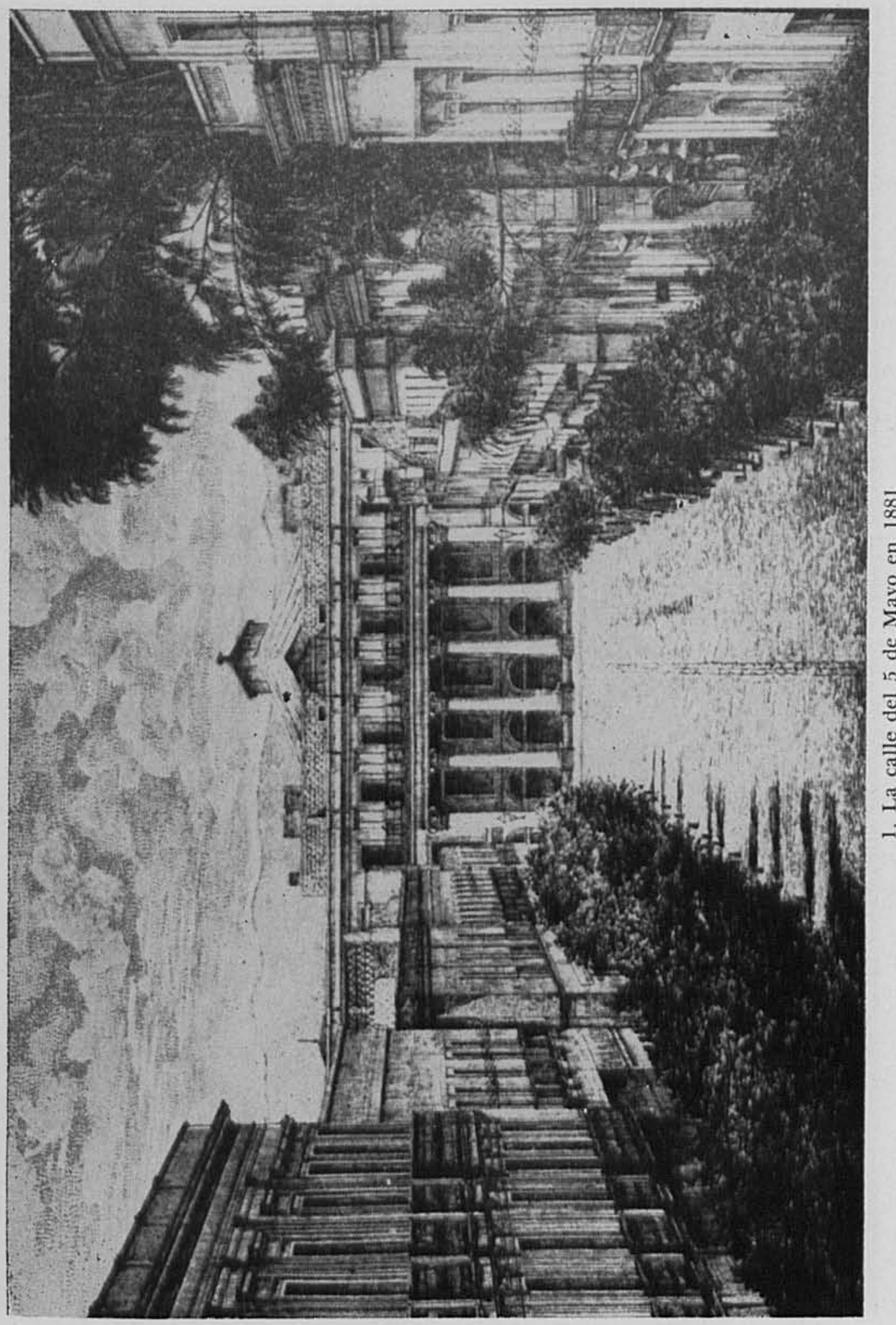




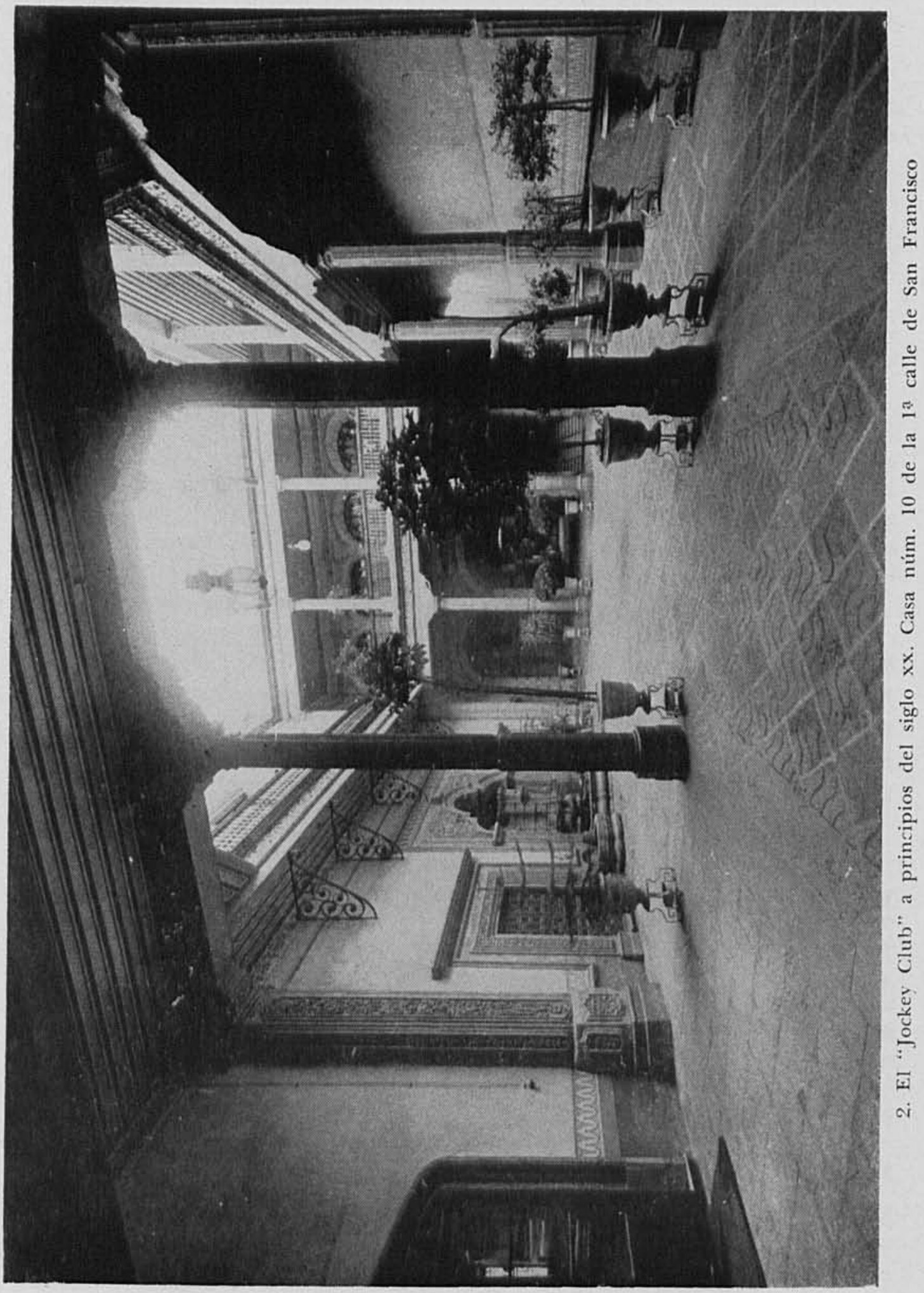


Respecto al problema que representa la paternidad de estas leyendas de Riva Palacio y Peza, cuáles son del general y cuáles de su ahijado y amigo - como llamaba Riva Palacio a Peza- Romero de Terreros y Millard Rosenberg se atienen a lo asentado por Luis González Obregón.

De acuerdo con el distinguido autor mexicano historiador y crítico don Luis González Obregón, todas las leyendas fueron escritas en varias sesiones en la casa de Riva Palacio, trabajando los autores en tan estrecha colaboración que el más profundo estudio de Tradiciones y leyendas, así como de todas las otras publicaciones de estos escritores, fallan en revelar la participación respectiva de cada uno de ellos en esta obra.

Cabe pensar que la inspiración, el conocimiento erudito, la imaginación y la elección de estos temas coloniales, que eran la salsa de Riva Palacio - recordemos sus novelas históricas, El libro rojo- deben atribuirse a Riva Palacio; en cuanto a la versificación de estas leyendas indudablemente la hicieron juntos. Tanto Riva Palacio como Peza eran magnificos versificadores, manejaban fácilmente diversos metros $\mathrm{y}$, desde luego, el octosilabo y la décima.

Al decir de Romero de Terreros y Millard Rosenberg, las Tradiciones y leyendas siguen el molde establecido por Angel de Saavedra, duque de Rivas (1791-1861) en sus conocidisimos Romances históricos.

La edición de Romero de Terreros de Tradiciones y leyendas se adorna con el retrato de Riva Palacio pintado por Manuel Ocaranza, que lo representa como general del ejército republicano durante la campaña contra la Intervención y el Imperio en Michoacán.

La nota biobibliográfica de Riva Palacio está tomada de Las Letras Patrias. México, 1900, de Manuel Sánchez Mármol y la de Juan de Dios Peza de La vida literaria de México. Luis G. Urbina. Madrid, 1917.

Se proporciona también una amplia bibliografía referente a la cultura mexicana en relación con las leyendas.

Entre los libros de arte cuya lectura se sugiere está México virreinal. Terreros and Rosenberg. New York, 1925, que tampoco se encuentra en las bibliografías de Romero de Terreros.

De cada una de las leyendas que figuran en la edición de Romero de Terreros y Millard Rosenberg, se da la noticia histórica, se estudia la métrica. En notas muy ricas se otorgan datos sobre los personajes, el nombre actual de las calles y otros pormenores que dan una idea más completa del ambiente colonial. Por último, el texto se acompaña de un copioso vocabulario. 
Tradiciones y leyendas mexicanas, como libro de texto para estudiantes de español, seguramente, cumplió la intención de Romero de Terreros y Millard Rosenberg.

El gusto por el pasado colonial que con sus novelas históricas, sus tradiciones y leyendas propició en México Vicente Riva Palacio, y en Perú Ricardo Palma, encontró eco en un historiador tan destacado como Luis González Obregón, quien desde las columnas de El Nacional (18911892) publicó artículos sobre la historia de México que más adelante reunió en sus muy populares y lédos libros México viejo y anecdótico (1891-1895) y Las calles de México (1922-1927).

González Obregón rindió homenaje a Riva Palacio, reeditando en unos pequeños tomos México a través de los siglos, que llamó Historia patria. Nueva edición de México a través de los siglos. J. Ballescá y Cía. Sin fecha.

Manuel Romero de Terreros, con su sello propio, siguió el sendero de Luis González Obregón y de paso, aunque ya más lejos, el que hạbia trazado Riva Palacio, en esa reconstrucción del pasado colonial, y puso un mayor énfasis en el arte del virreinato.

Como la mayoría de los intelectuales del xix y principios de este siglo, Romero de Terreros cultivaba el arte de la conversación. Tenía, también, un gran "sense of humor", gustaba del cuento fino y agudo, del que sugiere la maliciosa intención, y sabia contarlos con verdadera gracia.

Recuerdo con qué buen humor, comentaba y burlaba cuantas veces venfa a cuento aquel juicio que sobre su obra, Francisco de la Maza escribió allá por 1940 en su artículo "José Rodríguez Alconedo peripecias bibliográficas." 6

De la Maza al referirse a lo dicho por el marqués de San Francisco en su Arte colonial, Las artes industriales de la Nueva España, Historia sintética del arte colonial, afirma:

El marqués de San Francisco, nos habla brevemente, como todo lo suyo, de Alconedo, significándolo como cincelador y platero.

Al aparecer un nuevo artículo en los Anales o en alguna otra publicación, Romero de Terreros decia sonriendo a Francisco de la Maza:

- Anales del Instituto de Investigaciones Estéticas, núm. 6, Mexico, 1940, p. 11. 
"Paco, breve como todo lo mio." Y De la Maza daba muchas explicaciones, muchas disculpas. La escena volvía a repetirse en la próxima ocasión.

Los breves artículos de Romero de Terreros - como era costumbre en los años en que empezó a escribir- están destinados para publicarse en diarios y revistas. Con el tiempo reunió casi todos sus artículos en unos pequeños volúmenes, otros artículos quedaron fuera, no los consignó. Quiero hacer mención en estos Anales de algunos de esos breves, pero seductores artículos de Romero de Terreros.

El primer artículo que publicó Manuel Romero de Terreros fue en El Tiempo Ilustrado el 16 de abril de 1905. El Tiempo Ilustrado dirigido por Victoriano Agüeros era una de las revistas de mayor prestigio y circulación, en ella sobresalian Juan de Dios Peza, Rafael de Zayas Enrfquez y Manuel G. Revilla conisiderado como "el primer historiador mexicano de nuestras artes".

El año de 1905 en que Romero de Terreros da principio a su quehacer literario, se iniciaban en el mes de enero las obras de reparación y decorado de la catedral de México. Las bóvedas habian sido ya resanadas así como los entrepaños y muros de los costados. Las columnas se estaban limpiando y el coro sería reparado en su portada principal. La catedral conforme a la iniciativa del arźobispo Alarcón y, a sus expensas, iba a ser reparada en su arquitectura interior y exterior.

El 21 de marzo de 1905 el periódico El Tiempo publicó el artículo "El aseo y decorado de la catedral" firmado por Manuel G. Revilla. Se quejaba Revilla de que los trabajos dejaban mucho que desear, pues la persona encargada de ellos no tenia la habilidad suficiente. Asimismo, se quejaba de que con la nueva moda de raspar la cantera se dejaría al descubierto la piedra, la que quedaría sin resguardo y a merced del roce y la suciedad. Además, fundamentaba su oposición con otras razones de caracter artistico, por las que no deberfa quedar al descubierto la piedra en el interior de la catedral, ya que se verfan los remiendos hechos con bloques de piedra rosa, amarilla y de diversos grises, sin faltar la argamasa. Aunque la chiluca es el material en su mayor parte empleado - argumentaba Revilla- ya limpia da una tonalidad de un gris blanquecino que haria perder severidad a la construcción religiosa, y al dejar al descubierto la piedra se perderían las bellas líneas del edificio "que es uno de los mayores encantos que el edificio ofrece".

Para ello Revilla propone dar una uniforme y ligera capa de pintura 
a la piedra, imitando el color de la cantera levemente oscura, con objeto de lograr la homogeneidad del edificio.

Lo que más indignaba a Revilla no era tanto el raspar la chiluca, sino el intento de pintar las bóvedas y los muros de un verde tierno, pues ya se habian hecho las pruebas "en una parte del muro del coro frente por frente de la Capilla de la Soledad ,Qué desastre! |Adiós grandiosidad y carácter austero de nuestra Catedral!"

La catedral de México - sostenía Revilla- tiene ya bastante decoración.

Consiste en sus excelentes proporciones, en sus hermosas líneas, en la sobriedad del ornato, en contraposición con la riqueza de sus viejos retablos churriguerescos, $y$, en fin, en los grandes ornatos o relieves de piedra que tienen aquellas mismas bóvedas. Por toda la nave central corre una grandiosa greca en relieve; en cada bóveda de las naves procesionales aparecen fajas dividiéndolas en gajos, $y$, por último, cada capilla ostenta primorosos relieves de lacería. ¿Puede haber mejor decoración que ésta?... Lo prudente, lo juicioso y discreto en el caso, es limitarse a conservar conveniente $y$ decorosamente aseada la Catedral, y si se tienen fondos para ello restaurarla. Lo que está haciéndose y lo que se proyecta, no dará otro resultado que empeorar el suntuoso edificio, en vez de mejorarlo y embellecerlo.

El Imparcial de 24 de marzo reprodujo el artículo de Revilla. El 3 de abril de 1905 en El Pais, bajo el embozo de las iniciales KHNIT, se rebatió a Revilla. El articulista llamaba irónicamente técniço a Revilla, y se lanzó contra la idea de pintar los muros y columnatas diciendo que no se podía entregar a las generaciones futuras la catedral empastada "en cursi y miniado de almazarón". KHNIT rectificaba a Revilla en algunas de sus aseveraciones.

Tampoco es cierto que, en los trabajos de restauración de nuestra Catedral, se hayan desportillado las estrías de los pilares, ni padecido lo más minimón cornisamiento y arquivoltas. Todo lo contrario; ahora aparecen como son y como conviene que queden, para admirarlas en toda su pureza.

Revilla no contestó.

A sesenta y cuatro años de distancia de esa discusión, una nueva divide a los criticos de arte. Destruidos el coro y el Altar del Perdón por el incendio ocurrido en enero de 1967, unos criticos pretenden que se restaure el coro y el Altar del Perdón y otros, los de vanguardià, se oponen a la restauración. Para ellos lo destruido, destruido está: .. 
Volviendo a las revistas de gran importancia en el año de 1905 junto al Tiempo Ilustrado estaban Arte y Letras, dirigida por Ernesto Chavero. El Arte y las Ciencias. Revista Mensual de Bellas Artes e Ingenieria. Fundador y director Nicolás Mariscal. Arquitecto. El Mundo Ilustrado dirigido por Reyes Spíndola y después por el doctor Manuel M. Flores, contaba con la colaboración de Luis González Obregón, Ezequiel Chávez, Amado Nervo, José Juan Tablada, Luis G. Urbina, y otras firmas muy conocidas en esos años, amén de traducciones de los más famosos autores europeos.

Los Anales del Museo Nacional de Arqueologia, Historia y Etnologia y el Boletin de la Biblioteca Nacional que se habla comenzado a publicar en julio de 1904 dando a conocer obras ya muy raras sobre México, eran publicaciones muy apreciadas.

Uno de los más importantes acontecimientos culturales en el año de 1905 fue la celebración del tercer centenario de la aparición del Quijote.

El 21 de enero de 1905 El Imparcial reseñaba la sesión reglamentaria del "Liceo Altamirano" en el restaurant Sylvain. La sesión estuvo presidida por su presidente Joaquín D. Casasús y como presidente honorario Rafael Reyes Spindola, con la asistencia de los socios Pablo Macedo, Telésforo García, Salado Alvarez, Balbino Dávalos, Carlos Díaz Dufóo, Angel del Campo, Enrique Fernández Granados, Carlos Pereyra, Olavarria y Ferrari, Juan Sánchez Azcona, Juan B. Delgado, Roberto Esteva Ruiz, y otros. En la sesión se leyó "una carta hermosisima de Urbina", unas elegias del poeta latino Tibulo traducidas por Casasús, que fueron muy elogiadas por "su clasicismo y elegancia". Angel del Campo "Micrós" dio a conocer un capitulo de su "graciosísima novela La dama duende". En esta sesión del "Liceo Altamirano", se nombró a Telésforo García, Justo Sierra y José María Vigil para que estudiaran los temas a que se sujetaria el concurso convocado por el "Liceo Altamirano" para celebrar el tercer centenario del Quijote.

El 28 de enero los periódicos publicaron las convocatorias de la "Unión Iberoamericana" para el concurso con que se iba a solemnizar el tercer centenario de la obra de Cervantes. El tema era: "Estudio bibliográfico sobre El Quijote en América y critica de los trabajos hechos por americanos sobre el libro inmortal de Cervantes.

"Los trabajos deberán enviarse a la Unión Iberoamericana establecida en la calle de Alcalá. Núm. 65. Madrid."

Las celebraciones en México fueron muy lucidas. De ellas quedó una edición del Quijote. El Imparcial el 2 de junio de 1905 la anunciaba: 
una edición monumental, en magnífico papel y con ilustración de renombrados artistas españoles, y las celebérrimas de Gustavo Doré, por el infimo precio de $\$ 5.00$.

La colección completa de entregas contiene más de quinientas páginas con verdadera profusión de grabados. De venta en el despacho de periódicos de El Imparcial. Puente Quebrado 3 y 4.

El Mundo Ilustrado dedicó un número "dedicado a honrar la memoria del inmortal creador del Quijote", con artículos de Juan Valera, doctor Flores, José Maria Roa Bárcena y cuatro sonetos de Jesús E. Valenzuela.

Tal era, a grandes rasgos, el ambiente cultural de México en los primeros meses del año de 1905 en que Romero de Terreros empieza a ejercer su vocación de escritor con un primer artículo titulado "Aldos y Elzevirios Apuntes bibliográficos", para El Tiempo Ilustrado. Es un estudio sobre las ediciones que han alcanzado más renombre desde la invención de la imprenta hasta nuestros dias. Las más codiciadas por los bibliófilos son las publicadas - nos informa de las prensas Aldina y Elzeveriana en los siglos Xv, Xvi y xvir, famosas por sus ediciones de autores de la antigüedad clásica. "Aldos y Elzevirios" es un acucioso articulo sobre la historia, fundación y obra de las imprentas Aldina y Elzeveriana.

Después de este primer artículo, Romero de Terreros, no escribe sino hasta el año de 1912 para periódicos y revistas de México. Durante los años que van de 1905 a 1912 colabora en la Revista Aráldica de Roma. En 1909 sale de la imprenta de Manuel León Sánchez su libro Los condes de Regla. Apuntes biográficos. En 1911 escribe un artículo para los Anales del Museo Nacional: "Apuntes biográficos del Ilmo. Sr. D. Juan Gómez de Parada, obispo de Yucatán, Guatemala y Guadalajara."

En 1912, Romero de Terreros comienza a colaborar en Cosmos Magazine y los domingos en el suplemento ilustrado de El País. Diario Catrilico. Pro aris et focis certare. Fundado y dirigido por 'Trinidad Sánchez Santos.

Cosmos Magazine estaba dirigido por Manuel Sánchez León, editor del libro Los condes de Regla. Cosmos Magaxine, revista mensual. La suscripción costaba al año $\$ 6.00$, el semestre $\$ \mathbf{3 . 0 0}$ y el número suelto $\$ 0.50$. La revista se publicó de 1912 a 1922. La dirección se preciaba de las colaboraciones de escritores extranjeros, entre otros, Juan Maragall, Pierre Loti, Miguel de Unamuno. En Cosmos Magazine se publicó el artículo de Unamuno "Mi primera visión de México", en la que Unamuno cuenta cómo los relatos que su padre hacía de los años que tr* 
bajó en Tepic, fueron para él "una fuente de extraña poesía, y así es como las raíces de mi visión de México, se entrelazan con las ráces de mis primeros sueños".

Entre los colaboradores nacionales de Cosmos Magazine estaban José López Portillo y Rojas, Carlos Toro, Telésforo García, Ezequiel Chávez y de 1912 a 1913 Manuel Romero de Terreros quien firmaba indistintamente con su patronímico o con su título, marqués de San Francisco.

Cosmos Magazine se ufanaba de su sección bibliográfica en la que se comentaban los libros enviados por autores y editores. Uno de los libros allí comentados, sin una gran visión, fue el libro de Nicolás León, El negrito poeta. Cosmos juzgaba de esta manera el libro de León:

El negrito poeta, por el Dr. Nicolás León. Contribución al folklore nacional, llama el autor a este libro, que viene a ser una reproducción de calendarios publicados en diversas épocas con el nombre del famoso versificador repentista de los tiempos coloniales, quien, por la muestra, no se distingura ni por su ingenio, ni por su decencia. La edición está hecha por el Museo Nacional que bien podria ocuparse de cosas más útiles.

Cosmos Magazine se consideraba una revista de amplio criterio, que admitía la colaboración liberal, según se desprende de la contestación que su editor dio a La Esperanza, revista editada por los padres maristas. La Esperanza dedicó un larguísimo artículo a Cosmos Magazine quejándose de que esta revista pusiera junto a la firma del ilustrísimo señor doctor Antolín López Peláez obispo de Jaca, la de los escritores liberales Telésforo García y Ezequiel Chávez.

\section{Cosmos respondió aś a La Esperanza:}

No nos mortifica en nada, la observación del apreciable colega. Escrita en el ambiente místico de su orden y para los devotos a quienes está dedicada, parece lógica su observación, pero como nuestro magazine no ha sido ni aspira a ser una revista mística, vemos con gusto la observación del intransigente colega y seguiremos como hasta ahora nuestra labor, sin intransigencias innecesarias.

Cosmos es y será siempre católico, porque lo son tanto su director como todos los que toman una participación activa en su redacción, y el mismo señor obispo de Jaca, que hace poco nos dio una muestra de exquisito tacto visitando al autor de Electra D. Benito Pérez Galdós, no creemos que se habrá extrañado de ver su firma al lado de escritores que en nada atacaban los principios de la Iglesia. 
Éste era el espíritu de Cosmos Magazine en donde Romero de Terreros empezó a publicar en ese año de gobierno maderista y de inquietud para el país, el año de 1912.

En el mes de marzo escribió para Cosmos, "El rey sueña". Cuento en tres actos. El primer acto apareció en marzo, en abril el segundo y el tercero en mayo. "El rey sueña" no está registrado en las bibliografías de Romero de Terreros, ni tampoco su autor lo incluyó en su Teatro breve 1956, en donde reunió varias de sus obras teatrales.

La estampa "Damas mexicanas. Venus y las tres gracias" data del mes de mayo de 1912 (Cosmos Magazine). En ella se ocupó de doña Ignacia Rodriguez, más conocida como la Güera Rodríguez. La Güera y sus hijas famosas por su belleza, eran mentadas Venus y las tres gracias. Una de estas gracias, doña María de la Paz, sirvió de modelo -dice Romero de Terreros- a un cuadro de la Virgen de los Dolores que se conservaba en la iglesia de la Profesa.

El autor demuestra la simpatía de la Güera por la causa de la Independencia, y con buen humor disimula la conducta ligera que se achacaba a doña Ignacia Rodriguez. Dedicarle una crónica a la Güera se imponia, pues una de las hijas de esta Venus criolla, doña Josefa casó con el conde de Regla, don Pedro José Romero de Terreros y Rodriguez Sáenz de Pedroso, uno de los ilustres ancestros de Romero de Terreros.

Este conde de Regla era

nieto de aquel famoso conde que entre sus numerosas obras caritativas, dejó instituido el Monte de Piedad.

Todavia recuerdo el enfado de Romero de Terreros, cuando Artemio del Valle-Arizpe publicó su libro La Güera Rodriguez. México, 1949, en que hizo de la vida de doña Ignacia Rodríguez tema de literatura picaresca.

En octubre de 1912, Romero de Terreros con seguridad invitado por Manuel Sánchez León gerente de EI Pais, y por el director de este diario José Elguero, empezó a publicar en el suplemento ilustrado de los domingos de El Pais, una serie de artículos que llamó Ex-antiquis, sobre la vida y costumbres del virreinato. En estos artículos quedan ceñidos los mineros Borda, los cresos coloniales, las virreinas de la Nueva España, los cocheros del Santísimo, la casa del conde de Regla; personajes como don Fernando de Valenzuela y Enciso, conocido por "el duende", suceso de 1690, la historia de la "China", suceso de 1703, en este suceso comen- 
ta las vicisitudes de la rica heredera doña María Ignacia Cruzat, que de Filipinas llegó a la Nueva España para encontrar la muerte.

En estas delicadas y ágiles estampas coloniales muy a la manera de Riva Palacio, de Ricardo Palma -todavía se refiere, como estos autores lo hicieron, a sucedidos o sucesos- y más de cerca de Luis Gronzález Obregón, su muy amigo, la línea que Romero de Terreros habia de seguir a lo largo de su obra de tema colonial está aquí ya bien delineada: modestia, brevedad, gracia y un singular talento para sintetizar la historia y la anécdota.

Durante todo el año de 1913 siguen apareciendo cada domingo en El Pais los artículos coloniales de Romero de Terreros que van desde el 5 de enero hasta el 30 de diciembre. Artículos que con el tiempo recogerfa en un pequeño volumen con el mismo título de Ex-Antiquis, publicado en Guadalajara en 1919 y reeditado en 1944 con el nombre de Bocetos de la vida social en la Nueva España. En la edición de Guadalajara todavía puede leerse la estampa "La marquesa de Herrera", aparecida en El Pais el 8 de junio de 1913 en el apartado "Prosa selecta" y firmada por el marqués de San Francisco. "La marquesa de Hcrrera", al saber por qué motivo la suprimió en la edición de 1944. Acaso por haberla pubicado tres veces, una cuarta le parecería demasiada insistencia.

Esta crónica cuenta la historia de doña María Romero de Terreros Trebuesto y Dávalos de Bracamonte, que el año de 1787 mostró, ante un matrimonio de conveniencia, una decisión insólita en una dama de tan elevada alcurnia.

Urgida por su hermano el segundo conde de Regla para casarse con un hombre mucho mayor y exento de apostura, don Vicente de Herrera y Rivero, más tarde agraciado con el título de marqués de Herrera. obedeció a su hermano mayor, pero después de la boda se ocultó tres dias sin que nadie supiera su paradero, con las siguientes consiguientes hablillas de la nobleza novohispana y descrédito para el señor de Herrera. Durante el viaje a España que doña Dolores tuvo que hacer con el esposo no cruzó palabra con el marqués. Ya en la corte entró como dama de la reina María Luisa, pretexto que la alejó de su marido. Muerto, y muy a tiempo, el marqués de Herrera, doña Dolores encontró a don Manuel José de la Pedreguera, caballero de hábito de Alcántara, con quien casó ahora si, de grado, el año de 1799.

Los marqueses de San Francisco y Herrera que así se firmaban doña 
Dolores Romero de Terreros y su marido, sigue contando Romero de Terreros, se trasladaron a la Nueva España y aqui se establecieron:

en una antigua y almenada casa de la calle de la Cadena que, andando el tiempo, fue reconstruida y en la actualidad es propiedad del general Porfirio Diaz. *

Tuvieron los marqueses tres hijos: Juan que murió en la infancia; doña María que fue monja en el convento de Santa Isabel; y don Manuel de la Pedreguera y Romero de Terreros, muy conocido a mediados del siglo xix como marqués de la Pedreguera, aunque su verdadero título era de San Francisco. Murió este señor sin sucesión en 1878.

En los periódicos del siglo xix se menciona a don Manuel de la Pedreguera, como marqués de la Pedreguera, y después de la caída del segundo imperio como señor de la Pedreguera o antiguo marqués de San Francisco. La Orquesta de 12 de octubre de 1867 dice que el antiguo marqués de San Francisco era un hombre atento y benévolo.

En Vida Moderna. Semanario ilustrado, dirigido por Carlos González Peña, el 19 de enero de 1916, con el título "Crónicas de antaño. Un matrimonio de conveniencia", Romero de Terreros nuevamente cuenta la vida de la marquesa de Herrera.

En ese mismo año de 1913 Romero de Terreros vuelve a colaborar en Cosmos Magazine. El primer artículo que publica es del mes de marzo.

A su interés por la Colonia, Romero de Terreros aunó el gusto por las costumbres del siglo xix. En este artículo nos habla del Jockey Club en donde la elegante sociedad porfiriana, se reunía, y aunque Romero de Terreros no lo diga, uno de los pasatiempos de los socios era saborear la crónica escandalosa que había llegado rodando, rodando, desde el café de La Concordia.

Romero de Terreros narra sin muchos detalles la fundación del Jockey Club allá por 1881, siendo su fundador Pedro Rincón Gallardo, durante la presidencia del general Manuel González. Dice que el Club celebró sus primeras carreras el 22 de abril de 1882.

Esas primeras carreras fueron cinco y tuvieron lugar el día de la inauguración del Jockey Club, en los polvosos llanos de Peralvillo, el 22 de abril de 1882. El hipódromo había sido construido "con prontitud y elegancia".

En el año de 1882 uno de los acontecimientos que tenía impresionados

* En esta casa de Cadena 8, hoy Venustiano Carranza núm. 44 se levanta un espléndido y moderno edificio. El Banco de Comercio. 
y muy divertidos a los lectores de los periódicos, era la pugna a muerte entre metafísicos y positivistas, que en las columnas de los diarios se ponfan de todos colores. Al decir de los cronistas de la época, la pugna pasó a segundo término ante el anuncio de esa gran novedad que era el Jockey Club, que daría oportunidad a México de estar mano a mano con Europa hasta en los espectáculos. $Y$ todo el mundo se lanzó al hipódromo de Peralvillo, en mailcoach, vagón, vagoncito, coches alquilones o a pie.

Algunos de los espectadores de ese año de 1882, recordarían aquellas carreras que el circo Chiarini ofreció en marzo de 1867, en la Plaza de Toros del Paseo Nuevo, convertida en hipódromo, con la asistencia de lo más granado y florido de la sociedad mexicana. El señor Chiarini brindó al público grandes y magnificas carreras al estilo antiguo y moderno.

Carreras -decia el señor Chiarini- a la inglesa Steeple chase en su lenguaje propio, son la diversión favorita de los taciturnos lores y de toda la nobleza de la seria Albión; éstas serán ejecutadas vestidas y con la naturalidad más propia que desearse pueda.

Las carreras en el circo Chiarini fueron un éxito y tuvieron que repetirse varios domingos. El público olvidó por unas horas que muy cerca de la capital las armas de la República esperaban triunfar sobre el imperio de Maximiliano. Algunos años después, en 1882, teniamos, por fin, hipódromo.

Lástima que Romero de Terreros tampoco nos cuente la inauguración del Jockey Club y la carrera en que ganó el caballo "Halcón", propiedad del presidente González, y la manera como se presentaron las damas al hipódromo de Peralvillo.

Cuentan los comentaristas de esos años, que nuestras elegantes exageraron la nota en sus atuendos. Como las carreras era una diversión nueva, no supieron cómo vestirse y se arreglaron con trajes de fiesta, con joyas, se perfumaron, se peinaron con bandos planos pegados a la frente, con un rodete muy poco abultado que era colocado por encima de la nuca y adornado con una flor. Las damas de hermosa cabellera tuvieron la coquetería de ir sin postizos. Los sombreros de moda eran de paja de erizo, de paja tostada con adornos de terciopelo, campanillas azules, botones de oro, otros adornados con plumas, flores. Los de fieltro gxis claro se acompañaban con guantes de piel de Suecia. De todo se vio en el hipódromo ese día, el 22 de abril de 1882. 
Entre el calor del mes de abril, el viento y el polvo de Peralvillo -reían los cronistas- las damas regresaron a la ciudad blancas de polvo, sin necesidad de la toalla de Venus o del agua de Juvencio, despeinadas, en suma, hechas una desgracia.

Para 1883 apareció La Gaceta Hipica. Pablo Escandón era dueño de los mejores caballos de carrera y del mejor jockey. A esa segunda temporada las damas se vistieron con menos exageración con telas y vestidos comprados en la tienda de la "Sorpresa y Primavera unidas".

Poco a poco, las damas mexicanas fueron aprendiendo a vestirse para asistir a las carreras del Jockey Club, hasta llegar a esos alardes de refinado gusto, con trajes traidos ex-profeso de París que exhiblan en las carreras, como podemos ver en esas deliciosas fotografías de la belle èpoque de los años porfirianos.

En 1912, dice Romero de Terreros, el Jockey Club era dueño de un soberbio hipódromo, el de la Condesa, en donde anualmente se corría el Derby mexicano,

que atrae a las tribunas a todo el México elegante, y sin exageración de ninguna especie puede decirse que es el primer centro de reunión de la República.

Informa Romero de Terreros que, el Jockey Club en 1891, tomó en arrendamiento la histórica "Casa de los azulejos", propiedad de la señora Elena Idaroff de Iturbe.

Precisamente ese dia 16 de abril de 1905 en que Romero de Terreros publicó su primer artículo en México, El Imparcial se refería en un suelto al edificio del Jockey Club:

Se habían presentado algunas dificultades para el ensanche del edificio del Jockey Club, en la parte que da a la Avenida del Cinco de Mayo; pero lograron allanarse, y la fachada posterior se está levantando ya. Se ha procurado dar al estilo arquitectónico el sello colonial que domina en todo el edificio.

Los propietarios cedieron a la ciudad la faja de terreno que interrumpia el alineamiento de la calle, recibiendo, en cambio, el beneficio de la cons. trucción de la fachada, según nuestros informes.

Los escuetos datos que Romero de Terreros ha proporcionado sobre el Jockey Club han sido un mero pretexto para lo que en verdad le interesa: la historia, y la leyenda de la "Casa de los azulejos", así como la descripción arquitectónica del edificio. 
Ya con anterioridad, Luis González Obregón en El Partido Liberal (16 de septiembre de 1892) en un articulo de la serie "México Viejo", se habia detenido en la "Casa de los Azulejos". González Obregón llamaba la atención sobre lo sugestivo que serfa un estudio de la genealogia mexicana, especialmente para el historiador que pretendiera realizar una crónica completa de la Nueva España, basada en el conocimiento de varias calles y casas de nuestra capital que tienen su "historia en aquellos viejos blasones". Y a seguidas, González Obregón narra la historia del "palacio azul, como la sangre de sus antiguos moradores y de sus antiguos dueños".

Romero de Terreros recordando a González Obregón refiere la historia y la leyenda de este edificio. Da santo y seña de sus primeros poseedores y de su ascendencia; el porqué se llamó "Casa de los azulejos". Narra el porqué se llamó Plazuela de Guardiola. Vuelve sobre la conocida anécdota del sucedido en el callejón de la Condesa. Describe la "Casa de los azulejos", su arquitectura, y señala su valor dentro del arte colonial, asi como las modificaciones que ha padecido este hermoso edificio.

En Cosmos Magazine de 1913 encuentro dos obritas teatrales y un artículo que no fueron registrados en las bibliografias ya citadas. En febrero de 1913 apareció en Cosmos Magazine "La mujer blanca". Tragedia por Manuel Romero de Terreros. Marqués de San Francisco. En México al pie de los volcanes. Época actual. "La mujer blanca" concluyó en abril de 1913.

En el mes de marzo publicó otra pieza teatral "Más vale tarde que nunca. Proverbio de salón". Por el marqués de San Francisco.

La acción de "Más vale tarde que nunca". tiene lugar en alguna ciudad española, probablemente Madrid y a fines del siglo. Su tema y su trama son muy sencillos. El "proverbio" carece de pretensión.

"La mujer blanca" y "Más vale tarde que nunca" no fueron consignados por Romero de Terreros en su. Teatro breve 1956, eran de esos escarceos de cuyo nombre no queria acordarse.

En el mes de mayo escribió para Cosmos el artículo "Stonyhurst:" que no está en sus bibliografias.

"Stonyhurst" está dedicado al colegio en donde estudió. Romero de Terreros se ocupa de la historia de este Colegio, narra la peregrinación de los jesuitas que durante el reinado de Isabel I se vieron obligados a abandonar Inglaterra. Habla de los colegios que fundaron en el extranjero hasta que pudieron regresar a su patria y establecer el colegio de 
Stonyhurst, en el condado de Dorset. Desde luego, cuenta la historia del bello edificio, quiénes fueron sus dueños, hace la descripción arquitectónica del edificio, de sus cuidados jardines, de los objetos de arte que posee, de los cuadros de que el colegio se enorgullece con firmas tan ilustres como Murillo, Rubens, Van Dyck, y trípticos holandeses. También informa de la riqueza de la biblioteca, de los tesoros de la iglesia, y del observatorio meteorológico y astronómico del colegio, famoso en el mundo entero.

En este colegio de Stonyhurst - afirma Romero de Terreros- se educó la aristocracia inglesa, no poca de la francesa, austriaca, española y muchos mexicanos pertenecientes a las más aristócratas familias que figuraban en los años de auge del porfirismo.

Miembros de familias como

Escandón, de Landa, Amor, Romero de Terreros, Rincón Gallardo, Gómez de Parada, de la Cortina, Palomo, Diez de Vivanco, Martínez del Río, García Pimentel y otros, quienes conservan sin duda alguna, muy gratos recuerdos. de su antigua Alma Mater.

En Cosmos Magazine salió el mes de mayo el artículo "La Biblioteca Nacional" sin firma. Es la historia suscinta, pero muy documentada de. la Biblioteca Nacional desde los primeros intentos para establecerla en 1833-34 hasta el año de 1913. En este año de 1913 advierte el mal estado en que se encuentra la Biblioteca. Para bien de la cultura mexicana, hoy día la Biblioteca Nacional está totalmente reparada interior $y$ exteriormente y muestra la belleza de su fachada barroca del siglo xvir, también reseñada en este artículo por Romero de Terreros.

Tampoco firmó el artículo "El Quijote en América" publicado en junio de 1913 en la misma revista. Todavía fresco el recuerdo de las. fiestas y publicaciones que se hicieron con motivo del tercer centenario de la aparición del Quijote, Romero de Terreros se ocupa de la llegada a América del primer ejemplar de la novela cervantina, toma datos y anécdotas del libro México viejo de González Obregón y recuerda, al referirse a la primera edición del Quijote en América, al peruano $\mathbf{R i -}$ cardo Palma. La primera edición que se hizo en México fue en 1833, en casa de Mariano Arévalo.

No firmó el artículo "La ciudad de los palacios" (julio de 1913). Aquí hace la historia y descripción de los palacios coloniales que aún existen en la ciudad de México. En realidad, este artículo viene a ser una vehemente protesta contra la incuria y la destrucción que han 
sufrido los hermosos palacios coloniales, como la casa de los condes de Santiago de Calimaya que en 1913 estaba muy abandonada.

E1 México colonial se estaba yendo desde principios del siglo. El Imparcial de 5 de agosto de 1905 consignaba un suelto sobre la fiebre de destrucción que había en la ciudad de México.

El México Colonial se va. La fiebre de construcción y de reformas materiales que se ha despertado causa la destrucción de antiguas fincas de la época colonial que llamaban la atención, ya por algún suceso histórico relacionado con ellas o por su arquitectura arcaica y genuina.

Algunas de esas fincas tenían tableros y nichos con imágenes, emblemils religiosos y escudos heráldicos.

Quedan pocas fincas de la época colonial, que explican muy a las claras por la solidez de sus muros, la belleza de sus arcos y escaleras y la extensión de sus patios y zaguanes, que los ingenieros y arquitectos de entonces se preocupaban poco por el sitio y mucho menos por las reglas técnicas y por la estabilidad de sus obras.

La casa de los condes de Calimaya se restauró y se destinó en 1964 para Museo de la ciudad de México; el Hotel Iturbide actualmente está sienclo restaurado.

De aquella correspondencia que Mariano Riva Palacio sostuvo con la familia Romero de Terreros o dirigidas a otras personas, pero cuyo acervo posela Romero de Terreros, publicó una carta del entonces presidente del ayuntamiento de México, muy importante para la historia de nuestra ciudad. En ella Mariano Riva Palacio refiere la inauguración de las calles del Cinco de Mayo en 1868 . Esta carta la dio a conocer Romero de Terreros el 30 de abril de 1938 en la Revista Hoy.

Al triunfo de la República Mariano Riva Palacio, en diciembre de 1867, fue electo por voto popular presidente del ayuntamiento de México.

El periódico La Orquesta el 18 de diciembre de 1867 decla:

La población entera, los hombres de todos los colores políticos han aplandido el tino con que ha procedido la ciudad al hacer este nombramiento.

El señor Riva Palacio es uno de los inmaculados patriotas que forman la gloria de nuestras notabilidades políticas.

Unos meses antes de que Riva Palacio fuera electo presidente del ayuntamiento, La Orquesta habia hecho alusión el 28 de septiembre de 1867 al aspecto que presentaba la calle del Arquillo, cuyo nombre se habia cambiado por el de Cinco de Mayo, para celebrar el triunfo de México 
sobre los franceses. La calle del Cinco de Mayo recordaría ese triunfo en que los mexicanos hicieron gala de valor y de humanidad.

La calle del Arquillo a fines de 1867 se habia ensanchado hasta la calle de Vergara, hoy Bolivar y quedó cerrada por el Teatro Nacional.

La Orquesta, periódico de oposición, durante toda su vida fue bastante deslenguada, y ese 28 de septiembre con mucha energía y poco tacto político hacía sugestiones sobre la calle del Cinco de Mayo.

Cosa de siete años esa calle fue una teoria. En menos de ocho dias fue un hecho, y el público puede ya juzgar de la hermosa vista que presenta la fachada del Teatro Nacional, vista desde la calle de San José el Reai [hoy Isabel la Católica]. Lo que importa ahora, es que los escombros y ruinas que se han formado con el derrumbe de los edificios se convierta en hermosas y regulares fachadas. Aunque parezca un poco dura la providencia, el gobierno del distrito debe obligar a los propietarios a que comiencen a construir dentro de un mes, y concluyan a lo más tardar en un año bajo la pena de que si no lo verifican serán denunciables los terrenos para que otro fabrique $y$ cumpla esas condiciones. Si se le cortara un pedazo a la Alcaicería, qué hermosa quedaría esa calle.

¡Bueno estaba el gobierno de Juárez para atender a esas drásticas recomendaciones de La Orquestal

La mejora hecha a la ciudad de México con el propósito de conmemorar la batalla del Cinco de Mayo, tuvo una inauguración solemnísima y a ella se consagra Romero de Terreros, quien proporciona datos sobre el nombre de la calle del Arquillo llamada asi

por un arco que unia a las dos manzanas de casas propiedad del Marqués del Valle que se extendía desde la calle de Tacuba hasta la calle de Plateros [hoy Madero], era mucho más angosta que la actual, y con las de la Alcaicería (hoy primera y segunda de Ia Palma) divida en cruz el latifundio urbano que fundó Cortés. Algunas de estas casas todavía existen, aunque grandemente reformadas, siendo la principal el edificio que actualmente ocupa el Nacional Monte de Piedad.

Los primeros tramos de la calle de Cinco de Mayo se inauguraron el cinco de mayo de 1868. El presidente del ayuntamiento Mariano Riva Palacio, todavía emocionado por el éxito de la inauguración, el día nueve escribe una carta muy detallada de la festividad a un amigo residente en París. 
Demos gracias a Romero de Terreros por haber publicado esta carta, testimonio inestimable en su jugosa y genuina sencillez.

Escribe Riva Palacio:

Pasó el cinco de mayo, aunque me costó muchos trabajos e infinitas molestias el arreglar y dirigir todas las festividades que hubo en él, logré gracias a Dios que todo saliera muy bueno.

Riva Palacio sigue contando a su amigo que desde la madrugada la ciudad se despertó con los repiques, los cañonazos, las dianas, los gallos que recorrían las calles. A las ocho de la mañana puso la primera piedra del Hotel Guillow, en la esquina de la primera del Cinco de Mayo, antes portería de la Profesa, hotel que seria uno de los más elegantes de fines del siglo $x r x$.

A las diez de la mañana -prosigue Riva Palacio- el presidente con todas las autoridades, se dirigíó por las nuevas calles del Cínco de Mayo, enteramente concluidas y profusamente adornadas, cubriéndose el efecto de la falta de edificios que ahora se están levantando.

A la entrada de la calle, por San José el Real se levantó un lindo arco de triunfo y el Teatro Nacional, que cerraba la calle del Cinco de Mayo, se adornó "con elegancia y mucho gusto". El pórtico estaba precioso y allí escuchó el presidente Juárez el discurso del regidor Castillo Velasco y la poesfa de Justo Sịerra, "joven poeta de grandes esperanzas".

Después de estas ceremonias cerca de mil convidados disfrutaron de un banquete popular en la glorieta principal de la Alameda. Riva Palacio asegura en su carta que invitó desde el funcionario más conspicuo hasta el cargador y al aguador. Reuniendo de este modo a todas clases sociales que hicieron honor a la comida nacional.

Se les sirvió una comida enteramente nacional: artoz, asado, ensalada, chiles rellenos, mole de guajolote, verde y colorado, frijoles gordos con sus rábanos, etcétera, etcétera, y pulque blanco, de fresa y tuna colorada y de apio verde; presentando en tanta mesa, los botellones de cristal, los tres colores de nuestra bandera y un centro de flores y mucha fruta. El entusiasmo fue grande pero no mayor que el orden...

Después de la comida hubo baile; en las plazuelas, maromas, y los vitores recorrieron las principales calles de la ciudad. Por la noche frente a la diputación ardieron preciosísimos castillos "que agradaron infinito". Se estrenó esa noche el alumbrado de gas hidrógeno en la Plaza de 
Armas. Las companilas de teatro dieron sus mejores funciones, aludiendo en ellas a la victoria de la Patria en 1862. Las festividades terminaron a las dos de la mañana del día seis,

sin que hubiera habido -escribe el presidente del Ayuntamiento- el más pequefio insulto, el desorden mós insignificante.

Mariano Riva Palacio quedó muy satisfecho de la celebración del Cinco de Mayo. Los periódicos el día 6 informaron de las fiestas. El Monitor Republicano el 6 de mayo decia en su gacetilla

La calle del Cinco de Mayo. A la belleza del suntuoso arco que se construyó para engalanarla, daba mayor realce la arboleda que se plantó el mismo día en ambos costados de esta calle. De cada uno de estos árboles, y en dirección al de su frente, pendía una cuerda a una altura proporcionada, en la que estaban atados numerosos vasos de colores y multitud de linternas venecianas que presentaban una iluminación espléndida. Habla además porción de banderolas y gallardetes de las tres garantias, que en unión de las cortinas completaban el elegante adorno de la calle.

En un apartado más extenso El Monitor Republicano de esa fecha, comentaba las fiestas de inauguración de la calle de Cinco de Mayo. Inserta los discursos, la poesía de Sierra, los brindis pronunciados en el banquete popular por Garcia Torres, Rivera y Río, Pedro Ceballos. La descripción de la festividad la continúa El Monitor el día 7, en que proporciona más detalles y comenta la "bellfsima poesfa de Alfredo Chavero pronunciada en el Monumento levantado a Zaragoza en el panteón de San Fernando".

Si La Orquesta en 1867 proponía que se cortara la calle de Alcaicería para embellecer la calle del Cinco de Mayo, en 1881 se cumplía esta recomendación.

El periódico El Noticioso el 23 de mayo de 1881 obsequiaba a sus lectores un grabado de las calles del Cinco de Mayo, y en su gacetilla daba la explicación de este hermoso grabado, que aquí se reproduce, aunque es bien conocido.

\section{NUESTRA PRIMA DE MAYO}

Con el presente número repartimos a nuestros suscriptores la prima del Noticioso correspondiente al mes de Mayo.

Nuestra lámina representa las actuales calles del 5 de Mayo, sirviéndoles de fondo el gran Teatro Nacional. 
Creemos que este dibujo no carece de interts para nueatros suscriptones, porque realizandose precisamente en estos momentos la demolición de las casas de la Alcaicerla, para prolongar aquellas calles hacia el costada Oeate de la Catedral, muy pronto cambiará el aspecto de las actuales, al alineane con las dos nuevas vias que van a formar la futura y elegante avenida del 5 de Mayo.

Nuestro dibujo presenta, en primer término, a la derecha, una parte del gran hotel Comonfort; sigue inmediatamente, de la misma acera, el colegio de abogados, con sus gigantescos eucaliptus saltando sobre las verjas del jardín exterior; y al último, ya cerca del Nacional, vense los almacenes de la muy notable fábrica de calzado llamada La Elegancia. Del lado izquierdo se ve la hermosísima fachada lateral del hotel Guillow.

La calle del Cinco de Mayo, en 1901 -informa Romero de Terreros- se amplió hasta la calle de Santa Isabel y se tuvo que "derribar el hermoso coliseo construido por de la Hidalga y que primero se llamó de SantaAnna, después Imperial y luego Nacional".

En 1905 se iniciaron las obras para la construcción del gran Teatro Nacional, hoy Palacio de las Bellas Artes.

En febrero de 1905 hechas las excavaciones para la colocación de los cimientos del Gran Teatro Nacional, serán de hormigón y hierro, y es casi seguro que para fines del mes de octubre queden terminadas.

La obra de Romero de Terreros, plena de diferentes matices y temas, la constituyen breves artículos a los que puede aplicarse el refrán: "lo breve y bueno dos veces bueno".

Brevedad que es en este caso bondad de conocimientos, de información e investigación, de acopio de datos inéditos, de documentos soterrados que hizo públicos, de sintetismo y valor literario.

Justino Fernández el más amigo de Romero de Terreros en este Instituto, ve en esa brevedad, el modo de ser de Romero de Terreros, el reflejo de su modestia. Concebidos los artículos para ser publicados en diarios y revistas, la exigencia es lo conciso, no exenta de información y divulgación, Romero de Terreros cumplió esa exigencia con una notable habilidad para concretar y con un gran atractivo para interesar a los lectores, ya sean eruditos o legos. 
$\therefore$ En estos: Anales que se dedican. a la :memoria de Manuel Romero de Terreros; se reúnen varios artículos especializados sobre diversos aspectos de sù obra que dan una idea de lo que este autor de exquisitas y breves pièzas, que èn su conjunto reconstruyen en amplio panorama la vida, arte y costumbres de la colonia y en parte del siglo xix, representa para la cultura de México. 